\title{
Crown-scale evaluation of spectral indices for defoliated and discoloured eucalypts
}

\author{
K. M. BARRY*†, C. STONE $\$$ and C. L. MOHAMMED $\uparrow \S$ \\ $\uparrow$ School of Agricultural Science, University of Tasmania, Private Bag 12, Hobart, 7001 \\ Tasmania \\ \#Forest Resources Research, PO Box 100, Beecroft, NSW, 2119, Australia \\ $\S C R C$ Forestry, Private Bag 12, Hobart, 7001 Tasmania \\ - Ensis (the joint forces of CSIRO and SCION), Forest Protection and Biosecurity, \\ Private Bag 12, Hobart, 7001 Tasmania
}

(Received 29 October 2006; in revised form 3 February 2007)

\begin{abstract}
Remote sensing for evaluation of canopy health in plantation eucalypts is a realistic option for forest managers in the near future if reliable and robust methods of spectral analysis can be developed. Pot-grown eucalypts of three species important to the Australian plantation industry were used for crown-scale spectral (400-1000 nm) evaluations of vegetation indices as indicators of common symptoms of stress. When defoliation treatments (in E. globulus) or exposure to cold and nutrient deprivation (in E. pilularis) resulted in large differences in leaf cover, the red edge position and slope indices, two normalized difference vegetation indices (NDVIs), modified chlorophyll absorption ratio index 2 (MCARI2) or modified triangular vegetation index 2 (MTVI2) were most strongly correlated to leaf cover. However the NDVIs were significantly affected by soil background in a study with E. globulus. The percentage of red leaves resulting from stress treatment was most strongly correlated with the anthocyanin reflectance index (ARI) and red-green index (RGI) in both $E$. grandis and E. pilularis, however the RGI was affected by background type in the E. globulus study while the ARI was not. Exposure to cold and nutrient deprivation led to marked changes in leaf cover for $E$. pilularis but not in $E$. grandis and a much more reduced level of chlorophyll in $E$. pilularis than is suspected in E. grandis. In E. globulus, defoliation from the upper crown was easier to detect with spectral data than from the lower crown. Results were generally comparable to studies of eucalypt crown condition from native forests.
\end{abstract}

\section{Introduction}

\subsection{Detection of stress in eucalypts}

The possibility of routine assessments of forest canopy health utilizing remote sensing technologies has increased in recent years through advances in our understanding of the spectral reflectance properties of vegetation, including eucalyptus-dominated forests (Coops et al. 1997, 2003b, 2004, Datt 1998, 1999b, Stone et al. 2001, 2005, Pietrzykowski et al. 2006). During the growth of forest trees, a multitude of stressors (biotic or abiotic) can result in the development of stress symptoms (or strains) (Lichtenthaler 1996). The strain may be expressed as a

*Corresponding author. Email: Karen.Barry@utas.edu.au 
reduction in chlorophyll content, accumulation of secondary metabolites such as anthocyanins or loss of photosynthetic tissue (by defoliation or necrosis). All of these symptoms result in a consequential decrease in growth. Quantification of the location, extent and severity of these strains in plantation forests will enable this information to be integrated into forest management systems for timber growth and supply analysis.

Chlorophyll content is widely regarded as a generic indicator of plant stress (Carter 1993, Lichtenthaler 1996, Zarco-Tejada et al. 2002, Gitelson et al. 2003, Sampson et al. 2003) and methods to quantify chlorophyll content in eucalypts with remote sensing have been developed (Datt 1998, 1999b, Coops et al. 2003b). However, chlorophyll content can vary widely with leaf age in eucalypts (Choinski Jr et al. 2003, Close et al. 2004, 2005, Stone et al. 2005) and other genera (Mohammed et al. 2000, Sims and Gamon 2002). In eucalypts a common response to stress is production of anthocyanins, for example during photoinhibitory conditions (Close and Beadle 2003) or from biotic leaf damage (Stone et al. 2000, Smith et al. in press). Detection of anthocyanins is possible with remote sensing (Curran 1990, Gamon and Surfus 1999, Gitelson et al. 2001) and has been investigated in eucalypt forests to a limited extent (Coops et al. 2004, Stone et al. 2005).

In addition to alterations in leaf pigments, premature abscission of foliage, production of fewer and smaller leaves and contracted crowns can arise in eucalypts from abiotic (Pook 1985, Stone and Bacon 1994, Snowdon 2000, Thomson et al. 2001) or biotic damage (Shearer and Smith 2000, Stone et al. 2000, 2005, Stone and Coops 2004). These types of symptoms, which influence crown size and density, have a direct impact on biomass production of young eucalypt plantations (Jordan et al. 2002, Pinkard et al. 2006). Crown discolouration (chlorosis and/or redness) and defoliation (along with a reduction in leaf area index, LAI) are therefore two important indicators of stress in eucalypts. It is relevant to separate the effects of red discolouration from chlorosis and defoliation because seasonal and phenological changes in eucalypt leaves are often involved in a "red flush" of new growth which should not be considered part of response to poor health. Timely detection and spatial quantification of symptoms associated with stress will empower forest managers to make cost-effective decisions related to the management of underlying damaging processes.

\subsection{Vegetation indices for defoliation, leaf area index and red discolouration}

Total green biomass and related features of vegetation such as crown density, LAI and defoliation can be related to spectral information and most rely on the detection of chlorophyll content. While leaf pigments such as chlorophyll and anthocyanin absorb light in the visible wavelengths (Curran 1990, Curran et al. 1991, Gamon and Surfus 1999), the influences of leaf and crown structure are generally found in the near infrared (NIR) regions (Asner 1998). Vegetation indices (VIs) use information from both these wavelength regions to enable structurally normalized analysis of pigment content. We chose a number of published VIs to test relationships with symptoms exhibited by defoliated and stressed eucalypts (equations provided in table 1).

A recent test of 61 spectral indices for chlorophyll content against large databases of simulated and experimental spectra from various plant genera (le Maire et al. 2004) found that one of the best indices (DMI, table 1) was that developed with eucalypt leaves (Datt 1999b, Maccioni et al. 2001) and therefore this was included in 


Index

Table 1. Hyperspectral indices used in this study.

\begin{tabular}{|c|c|c|c|}
\hline Index & Equation & Comments & Reference \\
\hline Datt/Maccioni index (DMI) 犬ָ & $\mathrm{DMI}=\left(R_{780}-R_{710}\right) /\left(R_{780}-R_{680}\right)$ & Developed for chlorophyll & (Maccioni et al. 2001) \\
\hline Far red to red index $(\text { FRRI })_{\frac{r}{2}}^{\frac{+}{z}}$ & $\mathrm{FFRI}=R_{750} / R_{700}$ & Chlorophyll content & (Gitelson et al 1996) \\
\hline Lower red edge slope $\left(\mathrm{RE}_{\mathrm{ls}}\right)^{1} \sum_{\mathrm{e}}^{1}$ & $\mathrm{RE}_{\mathrm{ls}}=\left(R_{710}-R_{690}\right) /(710-690)$ & Chlorophyll content & $\begin{array}{l}\text { (Curran 1990, Coops } \\
\text { et al. 2004) }\end{array}$ \\
\hline Total red edge slope $\left(\mathrm{RE}_{\mathrm{T}}\right)^{1}$ 离 & $R \mathrm{E}_{\mathrm{T}}=\left(\mathrm{R}_{740}-\mathrm{R}_{690}\right) /(740-690)$ & Chlorophyll content & $\begin{array}{l}\text { (Curran 1990, Coops } \\
\text { et al. 2004) }\end{array}$ \\
\hline Normalised Difference & $\mathrm{NDVI}=\left(R_{\mathrm{NIR}}-R_{\mathrm{RED}}\right) /\left(R_{\mathrm{NIR}}+R_{\mathrm{RED}}\right) N D V I_{L A N D S A T}$ & Vegetation index for chlorophyll & (Rouse 1974) \\
\hline Vegetation Index (NDVI) & $\begin{array}{l}R_{\mathrm{RED}}=630 \text { to } 690 \mathrm{~nm}, R_{\mathrm{NIR}}=760 \text { to } 900 \mathrm{~nm} ; N D V I_{\text {narrow }} \\
R_{\mathrm{RED}}=645 \text { to } 655 \mathrm{~nm}, R_{\mathrm{NIR}}=755 \text { to } 765 \mathrm{~nm}\end{array}$ & and energy absorption & \\
\hline Red edge position (REP) & $\begin{array}{l}\text { Determined using first and second derivatives with the } \\
\text { Lagrangian interpolation method }\end{array}$ & Chlorophyll content & $\begin{array}{l}\text { (Demetriades-Shah } \\
\text { et al. 1990, Dawson } \\
\text { and Curran 1998) }\end{array}$ \\
\hline $\begin{array}{l}\text { Soil Adjusted Vegetation Ind } \\
\text { (SAVI) }\end{array}$ & $\begin{array}{l}\mathrm{xSAVI}=(1+\mathrm{L})\left(\mathrm{R}_{\mathrm{NIR}}-\mathrm{R}_{\mathrm{RED}}\right) /\left(\mathrm{R}_{\mathrm{NIR}}+\mathrm{R}_{\mathrm{RED}}+\mathrm{L}\right) \text {, where } L=0 \\
\text { for intermediate vegetation densities and the } \\
\text { NIR and RED bands are used as for NDVI }\end{array}$ & $\begin{array}{l}\text { Improved NDVI for influence } \\
\text { of soil. }\end{array}$ & (Huete 1988) \\
\hline Optimized SAVI (OSAVI) & OSAVI $=(1+0.16)\left(R_{800}-R_{670}\right) /\left(R_{800}+R_{670}+0.16\right)$ & $\begin{array}{l}\text { Improved SAVI, with single } \\
\text { wavelengths }\end{array}$ & (Rondeaux et al. 1996) \\
\hline $\begin{array}{l}\text { Combined index of TCARI } \\
\text { and OSAVI }\end{array}$ & $\begin{array}{l}\text { TCARI/OSAVI }=\{3[(\mathrm{R} 700-\mathrm{R} 670)-0.2(\mathrm{R} 700-\mathrm{R} 550) \\
(\mathrm{R} 700 / \mathrm{R} 670)]\} / \mathrm{OSAVI}\end{array}$ & $\begin{array}{l}\text { Reduces the effects of non- } \\
\text { photosynthetic materials and } \\
\text { soil for chlorophyll estimation }\end{array}$ & (Haboudane et al. 2002) \\
\hline $\begin{array}{l}\text { Modified chlorophyll } \\
\text { absorption ratio index } 2 \\
\text { (MCARI2) }\end{array}$ & $\operatorname{MCARI} 2=\frac{1.5\left[2.5\left(R_{800}-R_{670}\right)-1.3\left(R_{800}-R_{550}\right)\right]}{\sqrt{ }\left[\left(2 R_{800}+1\right)^{2}-\left(6 R_{800}-5 \sqrt{ } R_{670}\right)-0.5\right]}$ & $\begin{array}{l}\text { To calculate LAI with low } \\
\text { sensitivity to chlorophyll content, } \\
\text { atmospheric and soil effects }\end{array}$ & (Haboudane et al. 2004) \\
\hline $\begin{array}{l}\text { Modified triangular } \\
\text { vegetation index } 2 \text { (MTVI2) }\end{array}$ & MTVI2 $=\frac{1.5\left[1.2\left(R_{800}-R_{550}\right)-2.5\left(R_{670}-R_{550}\right)\right]}{\sqrt{ }\left[\left(2 R_{800}+1\right)^{2}-\left(6 R_{800}-5 \sqrt{ } R_{670}\right)-0.5\right]}$ & $\begin{array}{l}\text { To calculate LAI with low } \\
\text { sensitivity to chlorophyll content, } \\
\text { atmospheric and soil effects }\end{array}$ & (Haboudane et al. 2004) \\
\hline
\end{tabular}

Red-green index (RGI) ${ }^{1}$

$\mathrm{RGI}=\left(R_{600: 700}\right) /\left(R_{500: 600}\right)$.

Anthocyanin reflectance

$\mathrm{ARI}=\left(R_{550}{ }^{-1}\right)-\left(R_{700}{ }^{-1}\right)$

Anthocyanin content

(Gamon and Surfus 1999)

index (ARI)

Carter stress index $(\mathrm{CSI})^{1}$

$\mathrm{CSI}=R_{695} / R_{760}$

Generic detection of stress

(Carter 1994)

${ }^{1}$ These four indices were tested in a eucalypt crown health study with CASI data (Coops et al. 2004). 
our study. The spectral region known as the "red edge" (Curran 1990), which interfaces the visible and NIR, is particularly useful to characterize stressed vegetation and we used a number of indices with wavelengths from this region, including the slope and red edge position (REP, table 1) (Demetriades-Shah et al. 1990, Dawson and Curran 1998). Carter (1993) developed a "generic stress" index using wavelengths from the red edge which was consistently greater in plants stressed by a range of causes, compared to healthy plants. Assessments of remotely sensed indices for a mixed eucalypt species forest found that the total and lower slope of the red-edge were well correlated with crown density (Coops et al. 2004). These were used in our study (see table 1). Another simple algorithm using wavelengths from the red edge region was also tested (Gitelson et al. 1996).

The normalized difference vegetation index (NDVI), which was developed with the red and NIR wavebands available from Landsat data (Rouse 1974), can be correlated to green biomass and has been used to estimate LAI for a variety of vegetation types, including broadleaved forests (Fassnacht et al. 1997). A strong positive relationship between NDVI and LAI of a Eucalyptus maculata forest was shown (Coops et al. 1997) but effects of changing understorey were noted as a possible source of variation. As LAI in young eucalypt plantations is low, for example 2.3-3.8 in 2-3-year-old E. globulus (Tomé and Pereira 1991), the influence of changing soil or understorey composition may limit the use of NDVI. We tested NDVI with our data because it is a commonly used algorithm for many applications and suitable for broad wavelength band, multispectral instruments. We used wavelengths equivalent to Landsat bands as well as a narrow band alternative (table 1) similar to that used with the Digital Multi-Spectral Video (DMSV) in Australia, operated by Specterra Services Pty Ltd.

Several indices which adjust NDVI for atmospheric (Kaufman and Tanre 1992) and soil (Huete 1988) influences have been developed. These indices may be more reliable and less noisy than the NDVI (Rondeaux et al. 1996). Indices which have been designed to improve NDVI for background effects (SAVI, OSAVI, TCARI/OSAVI; table 1) were tested in our studies. Haboudane et al. (2004) developed vegetation indices to minimize the effect of leaf chlorophyll content on prediction of green LAI and the two best indices are further discussed here (MTVI2 and MCARI2, table 1). This may be particularly relevant for cases where trees are defoliated (e.g. by leaf chewing insects) but chlorophyll content within individual leaves does not change or increases in a compensatory manner (Pinkard et al. 2007) rather than decreasing which is more typical of most stress responses.

Green regions of leaf and canopy reflectance spectra are influenced by pigments such as anthocyanin and carotenoids in addition to chlorophyll content. A red-green index (RGI, table 1) has been well correlated with percentage leaf damage in eucalypts (Coops et al. 2004) and also to anthocyanin content (Gamon and Surfus 1999). The anthocyanin reflectance index (ARI, table 1) which was developed to detect anthocyanin content (Gitelson et al. 2001) uses similar wavelengths and both indices are tested here.

\subsection{A crown-scale approach}

The most common remote sensing approach for monitoring vegetation health has been to firstly develop robust spectral indices that are related to the symptom of interest and minimize extraneous influences. This approach is usually conducted 
through leaf-scale studies, using leaves with varying symptom levels or with varying concentrations of pigments such as chlorophyll (Carter 1993, 1994, Datt 1999a, Gamon and Surfus 1999, Mohammed et al. 2000, Maccioni et al. 2001, Stone et al. 2001, 2005, Coops et al. 2003b, Coops and Stone 2005, Pontius et al. 2005, Pietrzykowski et al. 2006). While diagnostic features of spectra from individual leaves contribute to assessment of tree crown health, reflectance of canopies is also influenced by whole-tree features such as foliar density, leaf shape and leaf orientation (Asner 1998) as well as non-vegetation components and background reflectance (Rondeaux et al. 1996, Zarco-Tejada et al. 2005). For example, a simple ratio index using reflectance at 850 and $710 \mathrm{~nm}$ was developed to predict chlorophyll content from a range of Eucalyptus species (Datt 1999b) and while predictions of chlorophyll content developed from remotely sensed data were moderately correlated with laboratory analysis of foliar chlorophyll content, the index was strongly affected by soil and water in mixed pixels (Coops et al. 2003b). Therefore vegetation indices developed with leaf-level relationships must be "scaled-up" to test their utility at the crown and canopy level.

Vegetation indices can be incorporated into the "scaling-up" process for remote sensing by a number of methods (Zarco-Tejada et al. 2001). These include direct application of leaf-level relationships between optical indices and leaf properties to the canopy-measured reflectance, often with single-crown delineation (Coops et al. 2003a, 2004). Alternatively, canopy reflectance can be investigated using canopy radiative transfer models such as SAILH (Verhoef 1984) which are coupled to leaf radiative transfer models, such as PROSPECT (Jacquemoud and Baret 1990, Jacquemond et al. 1996). Robust vegetation indices can then be developed on the basis of this synthetic data. Validation of the modelling methods show that they function well and have the ability to assess the performance of vegetation indices against a number of vegetation, environmental and atmospheric variables (Haboudane et al. 2004, Zarco-Tejada et al. 2004, 2005). However leaf models such as PROSPECT may benefit from further improvement (le Maire et al. 2004) and have not been tested to date for eucalypts.

Single-crown studies as a basis for developing spectral indices are rarely used, but represent an intermediate between leaf-scale and canopy-scale reflectance studies (Leckie et al. 1988, Yoder and Pettigrew-Crosby 1995). Gaining reflectance spectra from plant material at this level provides a simple way to test the influence of non-vegetation features and/or whole-tree alterations such as defoliation. One study of defoliation has assessed individual balsam fir crowns, in which single tree crowns with defoliation ranging from nil to complete were used. Ground vegetation was removed to simplify the data and a boom-arm held a spectroradiometer probe above each crown (Leckie et al. 1988). In the absence of hyperspectral imagery of stressed eucalypt plantations, this approach allows an investigation of whole-plant factors on reflectance at high spectral resolution, with the benefit that subject material can be manipulated and its condition accurately quantified. Constraints on using hyperspectral imagery at a suitable resolution for research in eucalypt plantations are currently based on cost. If there was no cost constraint, an alternative or additional method of developing indices for canopy health would be with airborne hyperspectral imagery and delineating trees for which ground-based information (e.g. LAI, extent of discolouration or defoliation) was collected (Coops et al. 2004) or with the canopy and leaf radiative transfer models discussed previously. 


\subsection{Objectives of this study}

In this study we investigated two important attributes presented as symptoms of crown damage; defoliation and discolouration. This was conducted with pot-grown Eucalyptus of three species important to the Australian plantation industry, using a spectroradiometer operating from 400 to $1000 \mathrm{~nm}$. In addition, use of an artificial substrate allowed for the effect of background surface to be tested. Digital photographs captured "crown-scenes" with a matching field of view to the spectroradiometer probe which were assessed using image analysis software. This enabled a measure of the projected leaf "cover" to be made and also proportions of discoloured leaves to be calculated. E. globulus, E. grandis and E. pilularis with varying crown conditions were used to test the effectiveness of a selected number of spectral indices.

\section{Methods}

\subsection{Plant material}

Six E. globulus saplings in $20 \mathrm{~cm}$ diameter pots were used. Plants were raised in an outdoor growing area, applied with slow-release fertilizer, irrigated daily and were all healthy in appearance. The plants were ca. 12 months old when used in January 2005. Average tree height was $112 \mathrm{~cm}$ (range $90-125 \mathrm{~cm}$ ) at this time. Plants were assessed with full foliage and were then subjected to a defoliation treatment. The top defoliation involved removing all leaves above a point on the stem at $50 \%$ of its length, while the bottom treatment removed leaves from below this point. As the lower stem (approx. $30 \mathrm{~cm}$ ) had no branches or leaves, the bottom treatment usually involved removal of less leaves in total than the top treatment. Therefore the two treatments will be referred to as "top/severe" and "bottom/moderate" defoliation.

Ten E. grandis plants of one clone were produced from cuttings prepared by Forests New South Wales from mother plants of Orara East provenance. Ten E. pilularis of one clone were similarly produced from mother plants of Queens Lake provenance. For both species, at ca. nine months of age, plants were transferred into $8 \mathrm{~cm}$ diameter pots, given slow-release fertilizer and kept in a glasshouse between 15 and $25^{\circ} \mathrm{C}$. Plants were later re-potted to $20 \mathrm{~cm}$ diameter pots. Half of the plants of each species were subjected to a "stress" treatment which involved placing them in an outdoor growing area for an eight-week period beginning on 12 April 2005 (mean minimum and maximum daily temperatures for June were 4.7 and $12.8^{\circ} \mathrm{C}$ respectively) and giving no additional fertilizer. As a consequence, the new leaves were red due to photoinhibitory conditions. Reddening of leaves due to anthocyanin production in eucalypts is a common response to low nutrition, low temperatures and high light (Close et al. 2001a, Close and Beadle 2003). In contrast, the "healthy" treatment consisted of keeping plants in a glasshouse at between 15 and $25^{\circ} \mathrm{C}$ and applying liquid fertilizer when needed. The new leaves of these plants were green and relatively soft.

Due to the different growing conditions of the treatments, height and form of the plants differed. The "stressed" E. pilularis were an average height of $85.6 \mathrm{~cm}$, while the "healthy" were $141.4 \mathrm{~cm}$ and a number of leaves had a tendency for curling due to the humidity of the glasshouse. The "stressed" E. grandis had an average height of $115.0 \mathrm{~cm}$, while the "healthy" plants averaged $111.3 \mathrm{~cm}$ in height. For all E. grandis, lower leaves exhibited a mild oedema condition and for the "healthy" plants the upper leaves also showed this symptom, possibly due to glasshouse 
humidity. At the time the experiment was conducted (early June 2005), plants were ca. 14 months old, based on the time cuttings were first made (March 2004). The plants had undergone approximately eight weeks of stress treatment by this time.

\subsection{Background surfaces}

A black canvas was used for all experiments as a background surface. Two different soils were also used as backgrounds with the E. globulus plants. A yellow mudstone soil ("bright") and a brown sandy soil ("dull") were both collected from an E. globulus plantation in the Barnback region of southern Tasmania. Soils were dried and sieved through a $9 \mathrm{~mm}$ mesh before use.

\subsection{Spectral analysis}

Reflectance data were obtained with a dual-channel spectroradiometer (UniSpecDC, PP Systems, Hammerhill, MA, USA) recording across the range of 300$1100 \mathrm{~nm}$ with a $3.1-3.4 \mathrm{~nm}$ sampling interval (dependent on wavelength), $3.7 \mathrm{~nm}$ resolution and $0.1 \mathrm{~nm}$ repeatability. The useful sampling range is between approx. $400 \mathrm{~nm}$ and $1100 \mathrm{~nm}$ due to the transmittance properties of the foreoptics. The dual channel system uses $2.1 \mathrm{~mm}$ diameter glass foreoptics; channel $1(\mathrm{CH} 1)$ had a cosine receptor (UNI435) attached and channel $2(\mathrm{CH} 2)$ had a $100 \mathrm{~mm}$ stainless steel ferrule covering a polished fibre tip (UNI684, $25^{\circ}$ field of view). Integration time was set to $200 \mathrm{~ms}$ and 20 scans were averaged for each recorded spectrum. A Spectralon $^{(\mathbb{I})}$ panel (PP Systems Hammerhill, MA, USA) was used as a white reference for spectrometer calibration. Data was collected on anintegral PC using UniWin-DC V1.5 software (PP Systems, Hammerhill, MA, USA).

To obtain reflectance measurements of individual crowns, trees were placed indoors in a small room sealed from external light and illuminated by four $150 \mathrm{~W}$ halogen globes which were equidistant from the crown centre. Halogen light sources provide a low and uniform irradiance over the spectral range of interest. A purposebuilt aluminium boom was attached to the ceiling and this included a mount for a digital camera and a fitting to hold the spectroradiometer fibre optic probe directly vertical. The camera lens was placed a close as possible to the fibre optic tip; approximately $3 \mathrm{~cm}$ horizontally and $2 \mathrm{~cm}$ vertically offset. The tree base was surrounded by a piece of plywood to provide a false background platform and cover the black plastic pot. The plywood was then covered by black canvas, or the two different soil types described previously for E. globulus. Soil was spread out evenly across the plywood at a depth of between 5 and $10 \mathrm{~mm}$. The probe was positioned $2.0 \mathrm{~m}$ above the background platform and therefore an area of the surface of radius $0.44 \mathrm{~m}$ was captured. A ring of black tubing was placed on the background which was equivalent to the field of view captured by the probe. This allowed the digital photograph image to be interpreted only for the approximate area sensed by the probe.

As the height of each plant varied, care was taken to ensure that approximately the same length of stem was exposed above the platform to provide uniformity. For the experiment with E. grandis and E. pilularis, the height of plants was altered so that a maximum of approx. $1 \mathrm{~m}$ of stem length was visible above the background platform. For example, the lip of the pots of "red" E. pilularis plants was positioned $5 \mathrm{~cm}$ below the platform, while the "green' $E$. pilularis were positioned between 60 and $66 \mathrm{~cm}$ below in order to expose only $1 \mathrm{~m}$ of stem length. For these taller plants, 
branches level with the platform were removed and those beneath it were not included in the experiment. As there was little difference between heights of the E. globulus plants, all plant pots were positioned at the same height, with the lip of the pot level to the background platform.

A number of indices were chosen for investigation with this data (table 1), as discussed in the introduction. Application of the MCARI2 and MTVI2 indices gave identical results, therefore they are presented together.

\subsection{Analysis of leaf material from digital photographic images}

Colour analysis was used to quantify different components (i.e. leaves as opposed to background) of the crown scene in the digital photographs, using WinFolia software (Regent, Canada). This allowed the area of different leaf colours (i.e. all shades of red, compared to all shades of green) to be separately quantified, or alternatively these could be added together to give total leaf cover visible in the crown scenes. This data relates to a two-dimensional plane of the field of view of the spectroradiometer, similar to measures such as the green vegetation fraction (horizontal density) used at a larger scale (Montandon and Small 2005). While leaf area index was not estimated for each plant, the data derived from the photographs ensures that only parts of the crown scanned by the spectroradiometer are included, because in some cases less than $100 \%$ of the crown width was enclosed by the field of view.

\subsection{Leaf pigments of $\mathrm{E}$. pilularis}

Three weeks after the stress treatment of the healthy and stressed clonal E. pilularis, leaves were destructively sampled for pigment analysis. Five leaves from leaf pairs 2 or 3 were selected from each of five plants of the stressed and healthy treatments.

Leaf discs were taken at three positions on the leaf to determine specific leaf area. The remainder of the leaf was immediately frozen at $-20^{\circ} \mathrm{C}$ until processing.

Leaves were allowed to thaw in the dark at $2^{\circ} \mathrm{C}$ for 30 minutes before processing. The leaf tissue was cut into thin slivers with scissors and a random subsample (150 $200 \mathrm{mg}$ ) was used. For chlorophyll extraction, leaf tissue was homogenized for approximately 30 seconds with a Polytron PT2100 (Kinematica AG, Switzerland) in $10 \mathrm{ml} \mathrm{80 \%}$ aqueous acetone ( $\mathrm{pH}$ adjusted to approximately 7.8 with $1 \mathrm{~N} \mathrm{NH}_{4} \mathrm{OH}$ solution), then a $5 \mathrm{ml}$ rinse of the homogenizer was added to the sample. Samples were stored in the dark at $2^{\circ} \mathrm{C}$ for two hours to extract, followed by centrifugation at $13000 \mathrm{rpm}$ for 10 minutes. Samples were diluted with acetone and absorbance was measured at 645 and $663 \mathrm{~nm}$ using a spectrophotometer (Cary 1E UV-Vis, Varian). Chlorophyll content was calculated using the following formulae (Arnon 1949): Chlorophyll a $(\mathrm{mg} / \mathrm{ml})=\left(0.0127 \times A_{663}\right)-\left(0.00269 \times A_{645}\right) ;$ Chlorophyll b $(\mathrm{mg} / \mathrm{ml})=\left(0.02269 A_{645}\right)-\left(0.00468 \times A_{663}\right)$.

Anthocyanin extraction was conducted with the remaining sliced leaf material. The thawed material (100-150 mg) was homogenized as above but with $6 \mathrm{ml}$ of acidified methanol (40 $\mathrm{ml}$ of concentrated $\mathrm{H}_{2} \mathrm{SO}_{4}: 1760 \mathrm{ml}$ of methanol) and a $3 \mathrm{ml}$ rinse was added to the sample. Samples were heated to the point of gentle boiling in a hot water bath for 1.5 minutes (Close et al. 2001b). Samples were then left at $2{ }^{\circ} \mathrm{C}$ in the dark for approximately 10 hours to extract and then centrifuged for 10 minutes at $13000 \mathrm{rpm}$. Any necessary dilutions were made and absorbance at wavelengths 530 and $657 \mathrm{~nm}$ was measured as above. Anthocyanin content was 
calculated using the following formula (Mancinelli et al. 1975) and results were expressed as $\mu \mathrm{g} \mathrm{cm}^{-2}$. Total anthocyanin content $=A_{530}-\left(0.25 \times A_{657}\right)$.

\subsection{Statistics}

All statistics were completed with Genstat for Windows (Genstat 2003). One-way ANOVA were used to compare data from plants assessed with different background surfaces and for the E. grandis and E. pilularis stress experiments. Analysis of the defoliation study was complicated by the fact that the controls (before defoliation) were not independent from the defoliation treatment, so an ANOVA could not be performed. That is, spectra were first collected from the plants with full foliage, then they were defoliated and spectra were obtained again. For this reason the difference between results before and after defoliation was determined for each type of defoliation (top or bottom) then a $t$-test was conducted which compared these differences. For all datasets, linear regressions were performed to correlate spectral indices with leaf area data. Significant differences were assessed at the 5\% level.

\section{Results and discussion}

\subsection{Effect of defoliation pattern for E. globulus}

While the same length of stem (i.e. 50\%) was defoliated in the bottom and top defoliation treatments, the crown scene photographs revealed that the treatments had a very different effect on how much foliage was visible (horizontal density) from above the crown (figure 1). Leaf analysis from the photographs showed that there was little difference in visible leaf cover after defoliation when leaves were removed from the bottom of the plants, whilst a large difference when plants were defoliated from the top ( $t$-test $P=0.008$, table 2). The top defoliation treatment reduced the horizontal foliage density to less than two-thirds of that of a healthy plant (table 2).

Overall reflectance brightness was more substantially reduced by defoliating the tops of the crowns than for the removal of lower crown foliage (figure 2) and this was particularly pronounced in the NIR plateau. This is unlike balsalm fir in which
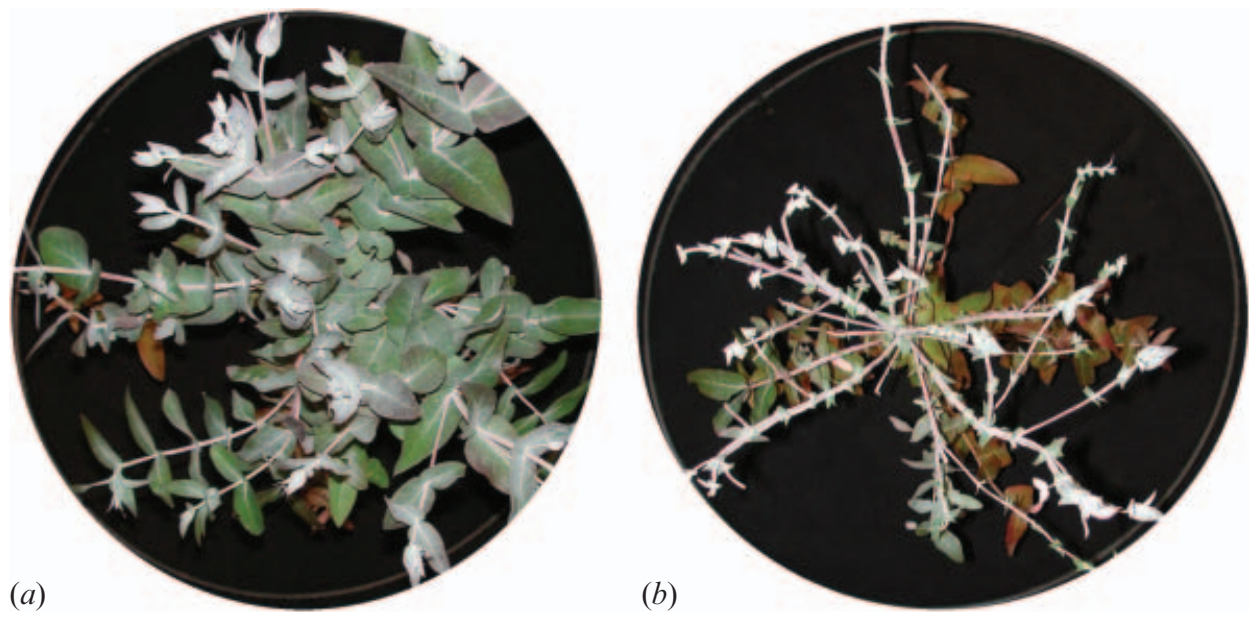

Figure 1. Examples of crown scenes obtained from photographs taken $2 \mathrm{~m}$ above the substrate, related to the spectroradiometer field of view; (a) E. globulus with black canvas background. (b) The same E. globulus after 50\% "top/severe" defoliation. 
Table 2. Leaf cover percentage and averaged values $( \pm$ SE) of spectral indices $(n=3)$ for healthy $E$. globulus when subjected to two different defoliation treatments. OSAVI, SAVI an 흘 for the top and bottom treatments.

\begin{tabular}{|c|c|c|c|c|c|c|c|c|}
\hline & \multicolumn{3}{|c|}{ 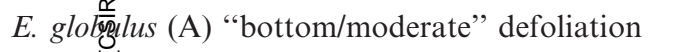 } & \multicolumn{3}{|c|}{ E. globulus (B) "top/severe" defoliation } & \multicolumn{2}{|c|}{ Statistical analysis } \\
\hline & Befordefoliation & Defoliated & Difference & Before defoliation & Defoliated & Difference & $P(t$-test $)$ & $r^{2}(\%$ leaf cover $)$ \\
\hline Image analysis & $\frac{\bar{d}}{\pi}$ & & & & & & & \\
\hline Leaf cover $(\%)^{1}$ & $61 \frac{0}{\frac{\pi}{3}} 8( \pm 2.11)$ & $59.3( \pm 1.35)$ & 2.6 & $62.1( \pm 5.07)$ & $38.1( \pm 4.58)$ & 24.0 & $* *$ & - \\
\hline Reflectance indices & ฉ̄ & & & & & & & \\
\hline NDVI $_{\text {LANDSAT }}$ & $0.78( \pm 0.01)$ & $0.77( \pm 0.01)$ & 0.01 & $0.78( \pm 0.00)$ & $0.68( \pm 0.00)$ & 0.10 & $* * *$ & $0.81 * * *$ \\
\hline $\mathrm{NDVI}_{\text {narrow }}$ & $0.59( \pm 0.02)$ & $0.57( \pm 0.02)$ & 0.02 & $0.59( \pm 0.01)$ & $0.44( \pm 0.01)$ & 0.15 & $* * *$ & $0.78^{* * *}$ \\
\hline MCARI2 or MTVI2 & $0.29( \pm 0.01)$ & $0.28( \pm 0.01)$ & 0.01 & $0.30( \pm 0.03)$ & $0.15( \pm 0.02)$ & 0.15 & $* *$ & $0.98^{* * *}$ \\
\hline DMI & $0.47( \pm 0.03)$ & $0.47( \pm 0.03)$ & 0.00 & $0.50( \pm 0.02)$ & $0.33( \pm 0.01)$ & 0.17 & * & $0.68 * * *$ \\
\hline FRRI & $2.13( \pm 0.11)$ & $2.08( \pm 0.11)$ & 0.05 & $2.19( \pm 0.06)$ & $1.52( \pm 0.03)$ & 0.68 & * & $0.75^{* * *}$ \\
\hline $\mathrm{RE}_{\mathrm{ls}} \times 100$ & $0.48( \pm 0.02)$ & $0.45( \pm 0.02)$ & 0.03 & $0.45( \pm 0.05)$ & $0.28( \pm 0.03)$ & 0.17 & * & $0.93 * * *$ \\
\hline $\mathrm{RE}_{\mathrm{T}} \times 100$ & $0.38( \pm 0.02)$ & $0.36( \pm 0.02)$ & 0.02 & $0.38( \pm 0.03)$ & $0.18( \pm 0.02)$ & 0.19 & * & $0.97 * * *$ \\
\hline RGI & $0.81( \pm 0.01)$ & $0.82( \pm 0.01)$ & -0.01 & $0.81( \pm 0.01)$ & $0.88( \pm 0.01)$ & -0.07 & ** & $0.77 * * *$ \\
\hline REP & $703.89( \pm 0.86)$ & $704.12( \pm 0.97)$ & -0.22 & $705.08( \pm 0.46)$ & $697.07( \pm 1.09)$ & 8.01 & * & $0.98^{* * *}$ \\
\hline ARI & $1.73( \pm 0.21)$ & $1.77( \pm 0.21)$ & 0.04 & $1.69( \pm 0.22)$ & $2.44( \pm 0.44)$ & -0.75 & $N S$ & $0.55^{* *}$ \\
\hline CSI & $0.41( \pm 0.02)$ & $0.42( \pm 0.02)$ & -0.01 & $0.40( \pm 0.01)$ & $0.61( \pm 0.01)$ & -0.21 & * & $0.82^{* * *}$ \\
\hline
\end{tabular}

${ }^{1}$ Percentage of field of view.

${ }^{* * *} P<0.001$. ${ }^{* *} P<0.01$. ${ }^{*} P<0.05$. ${ }^{\mathrm{NS}}$ Not significant. 


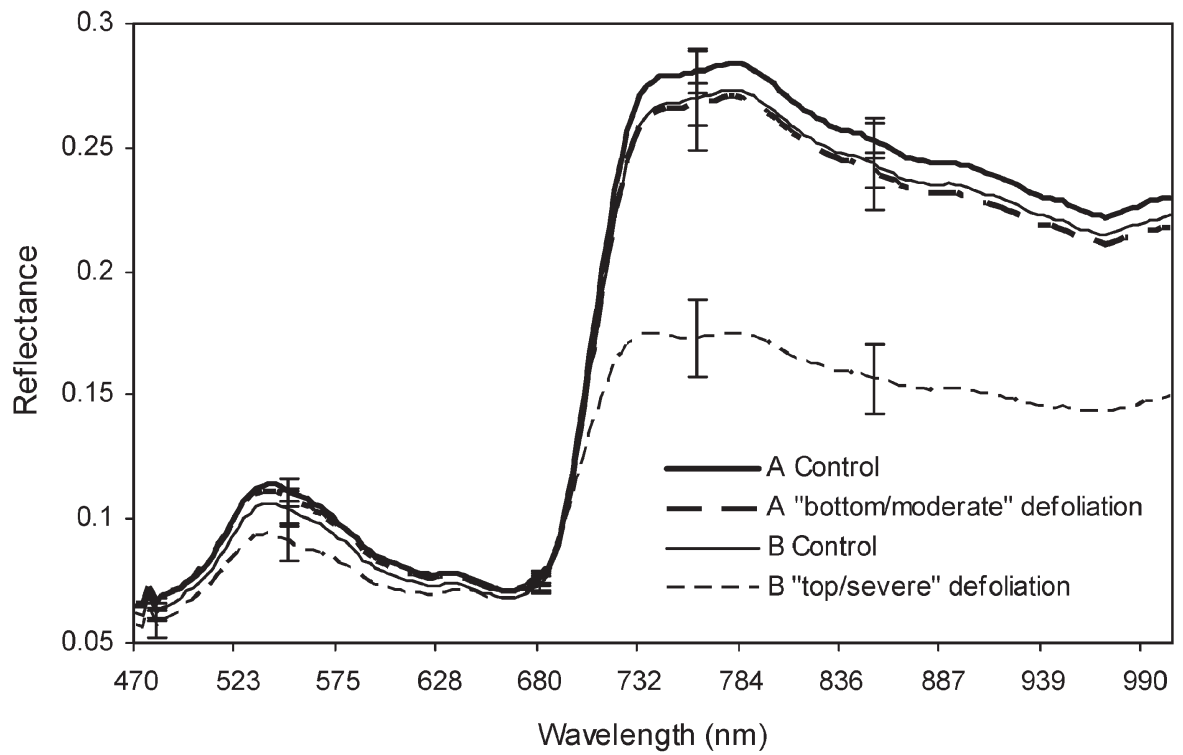

Figure 2. Averaged spectra $( \pm \mathrm{SE})$ for two sets of $E$. globulus plants $(A, B)$ which were defoliated with either of two different treatments.

reflectance was increased in the UV/VIS wavelengths but decreased in the NIR when defoliation became progressively more pronounced (Leckie et al. 1988), a trend which was also apparent for moderate to severely defoliated hemlock (Pontius et al. 2005). Decreased reflectance across the spectrum in our study may be due to the black background used and if a typical soil was used the lighter background would result in a different result. Decreased reflectance in the NIR region often indicates a change in the leaf or crown structure (Gitelson et al. 2002) which is commensurate with a loss of leaf area, however the visible wavelengths relate more specifically to pigment content. The reports of hemlock and balsam fir were naturally-induced declines involving foliage undergoing varying stages of chlorosis and defoliation and therefore spectral alterations in the UV/VIS region of the spectrum would be expected. As our study used artificial defoliation, there was no other stress effect on the remaining leaves and therefore less change in the UV/VIS regions of the spectra may be expected than if the remaining leaves were discoloured or damaged.

The $t$-test showed that for all indices the difference between the plants before and after defoliation with the top defoliation treatment was significantly greater than that for the bottom defoliation treatment (table 2). This would be expected as a result of both greater extent of leaf removal but also the pattern of removal. The broad and narrow band NDVI had the greatest statistical difference $(P<0.001)$ while other indices were between $0.003<P<0.027$ or not significant in the case of the ARI. Correlations between leaf cover with each index showed that all were significantly correlated but the red edge slope and position indices and MCARI2 (or MTVI2) were the most strongly correlated. Using PROSPECT and SAILH models to simulate their data, Haboudane et al. (2004) also found that MCARI2 and MTVI2 generated similar but robust results in terms of estimating green LAI. 
This study demonstrates that the VIS/NIR spectrum is sensitive to foliage loss from the top of the crown. Detection of loss from the upper crown is important for monitoring the effects of defoliation on growth, as studies of artificially defoliated young E. globulus in Tasmania showed that loss of all leaves in the upper $50 \%$ of the crown resulted in a dramatically greater effect on growth compared to loss of leaves in the lower $50 \%$ of the crown (Pinkard et al. 2006). Defoliation of tree crowns may occur in a number of patterns depending on the causal agent. For example in E. globulus, damage by the Mycosphaerella spp. fungi results primarily in loss of the older leaves in the lower crown (Carnegie and Ades 2000), while insect pests such as Crysomelids or Gonipteris spp. feed on new leaves, with loss most conspicuous in the upper crown (Loch and Floyd 2001). Further studies of this nature may be useful to discern to what extent damage to various parts of the crown can be detected using reflectance data.

Curran (1990) found no relationship between the red edge and chlorophyll content of whole canopies, due to the influence of understorey vegetation. However, Coops et al. (2004) found that the $\mathrm{RE}_{\mathrm{T}}$ and $\mathrm{RE}_{\mathrm{ls}}$ were well correlated with crown density when individual tree crowns were delineated in high resolution imagery and the reflectance data extracted for analysis. This agrees with results found here for E. globulus as the $\mathrm{RE}_{\mathrm{ls}}$ and $\mathrm{RE}_{\mathrm{T}}$ were very strongly correlated with leaf cover, as was the REP.

\subsection{Comparison of healthy and stressed (discoloured) E. grandis and E. pilularis}

Exposure to cold conditions and deprivation of nutrients (the "stress" treatment) resulted in red discolouration of the youngest leaves for both E. grandis and E. pilularis. Plants which remained indoors and were provided with nutrients (the "healthy" condition) did not develop any red discolouration. The stress treatment resulted in reduced growth of $E$. pilularis, such that the plants had significantly less (approximately two-thirds) of the leaf cover compared to the healthy plants (table 3). This is in contrast to E. grandis which maintained a similar (not significantly different) leaf cover to the healthy plants (table 4). Other studies of young $E$. grandis have shown that nutrient stress has little effect on growth (Rolando and Little 2003) which may explain the difference between the species here. These different responses to the stress treatment allow comparison of the effects of red discolouration (the percentage of which was essentially identical in both species, table 3 ) in reflectance spectra from single crowns with or without leaf cover reduction.

During the period of stress exposure, leaves of the E. pilularis plants were assessed for pigment content and specific leaf area. After three weeks of stress treatment the chlorophyll content of young leaves was approximately seven times less than corresponding leaves of the healthy plants, while anthocyanin content was over 3 times greater and specific leaf area was halved (table 5). While the crown spectra were acquired eight weeks after the stress treatment began, the pigments data from the three week analysis indicates that there were likely to be substantial differences in these factors also at eight weeks. This highlights that while leaf reddening was the "visible symptom" of the young leaves of stressed plants, anthocyanin accumulation is not the only change occurring which will affect the reflectance spectra (Karageorgou and Manetas 2006). Similar leaf assessments were not made for E. grandis therefore it is unknown if alterations in chlorophyll and anthocyanin content and specific leaf area were of a similar magnitude to E. pilularis. While 
Table 3. E. pilularis leaf cover data and average values $( \pm \mathrm{SE})$ for spectral indices $(n=5)$ for healthy and stressed plants assessed eight weeks after the stress treatment with $P$ values for one-way ANOVA and correlation coefficients $\left(r^{2}\right)$ between indices and total leaf cover or the red leaf cover.

\begin{tabular}{|c|c|c|c|c|c|}
\hline & Healthy & Stressed & $P$ & $r^{2}(\%$ leaf cover $)$ & $r^{2}(\%$ red $)$ \\
\hline \multicolumn{6}{|l|}{ Image analysis } \\
\hline Total leaf cover ${ }^{1}$ & $39.8( \pm 1.6)$ & $25.6( \pm 2.5)$ & $* *$ & & \\
\hline Green & $39.8( \pm 1.6)$ & $12.5( \pm 1.0)$ & $* * *$ & & \\
\hline Red & 0 & $13.2( \pm 1.6)$ & $* * *$ & & \\
\hline \multicolumn{6}{|l|}{ Reflectance indices } \\
\hline NDVI $_{\text {LANDSAT }}$ & $0.81( \pm 0.00)$ & $0.73( \pm 0.01)$ & $* * *$ & $0.89^{\mathrm{NS}}$ & $0.72^{\mathrm{NS}}$ \\
\hline $\mathrm{NDVI}_{\text {narrow }}$ & $0.57( \pm 0.03)$ & $0.43( \pm 0.03)$ & $* *$ & $0.94 * * *$ & $0.85^{\mathrm{NS}}$ \\
\hline MCARI2 or & $0.20( \pm 0.01)$ & $0.14( \pm 0.01)$ & $* *$ & $0.92 * * *$ & $0.40^{\mathrm{NS}}$ \\
\hline MTVI2 & & & & & \\
\hline DMI & $0.56( \pm 0.01)$ & $0.29( \pm 0.01)$ & $* * *$ & $0.81^{* * *}$ & $0.59^{* * *}$ \\
\hline FRRI & $2.43( \pm 0.06)$ & $1.59( \pm 0.04)$ & $* * *$ & $0.86^{* * *}$ & $0.30^{* *}$ \\
\hline $\mathrm{RE}_{\mathrm{ls}} \times 100$ & $0.25( \pm 0.01)$ & $0.28( \pm 0.02)$ & NS & $0.00^{\mathrm{NS}}$ & $0.53^{*}$ \\
\hline $\mathrm{RE}_{\mathrm{T}} \times 100$ & $0.24( \pm 0.01)$ & $0.18( \pm 0.01)$ & $* *$ & $0.93 * * *$ & $0.72^{\mathrm{NS}}$ \\
\hline RGI & $1.29( \pm 0.01)$ & $1.07( \pm 0.01)$ & $* * *$ & $0.70^{* *}$ & $0.85^{* * *}$ \\
\hline REP & $710.23( \pm 1.18)$ & $694.98( \pm 1.16)$ & $* * *$ & $0.85^{* * *}$ & $0.66^{* *}$ \\
\hline ARI & $2.65( \pm 0.35)$ & $6.17( \pm 0.49)$ & $* * *$ & $0.68 * *$ & $0.72 * *$ \\
\hline CSI & $0.36( \pm 0.01)$ & $0.56( \pm 0.02)$ & $* * *$ & $0.89 * * *$ & $0.65^{* *}$ \\
\hline
\end{tabular}

${ }^{1}$ Percentage of field of view.

${ }^{* * *} P<0.001 .{ }^{* *} P<0.01 .{ }^{*} P<0.05$. ${ }^{\mathrm{NS}}$ Not significant.

Table 4. E. grandis leaf cover data and average values $( \pm \mathrm{SE})$ spectral indices $(n=5)$ for healthy and stressed plants assessed eight weeks after the stress treatment with $P$ values for one-way ANOVA and correlation coefficients $\left(r^{2}\right)$ between indices and total leaf cover or the red leaf cover.

\begin{tabular}{|c|c|c|c|c|c|}
\hline & Healthy $^{2}$ & Stressed & $P(\mathrm{ANOVA})$ & $\begin{array}{l}r^{2} \text { (total } \\
\text { leaf cover) }\end{array}$ & $r^{2}(\%$ red $)$ \\
\hline \multicolumn{6}{|l|}{ Image analysis } \\
\hline Total leaf cover ${ }^{1}$ & $23.6( \pm 2.1)$ & $21.9( \pm 1.4)$ & NS & & \\
\hline Green & $23.6( \pm 2.1)$ & $8.9( \pm 1.2)$ & $* * *$ & & \\
\hline Red & 0 & $13.1( \pm 0.7)$ & $* * *$ & & \\
\hline \multicolumn{6}{|l|}{ Reflectance indices } \\
\hline NDVI $_{\text {LANDSAT }}$ & $0.74( \pm 0.01)$ & $0.72( \pm 0.01)$ & $*$ & $0.64 * * *$ & $0.43^{\mathrm{NS}}$ \\
\hline $\mathrm{NDVI}_{\text {narrow }}$ & $0.39( \pm 0.02)$ & $0.34( \pm 0.01)$ & * & $0.66^{* *}$ & $0.46^{*}$ \\
\hline MCARI2 or & $0.14( \pm 0.01)$ & $0.11( \pm 0.0)$ & $* *$ & $0.50^{*}$ & $0.67 * *$ \\
\hline DMI & $0.38( \pm 0.02)$ & $0.32( \pm 0.01)$ & * & $0.13^{\mathrm{NS}}$ & $0.64 *$ \\
\hline FRRI & $1.72( \pm 0.05)$ & $1.57( \pm 0.02)$ & * & $0.42^{\mathrm{NS}}$ & $0.52 *$ \\
\hline $\mathrm{RE}_{\mathrm{ls}} \times 100$ & $0.23( \pm 0.01)$ & $0.20( \pm 0.01)$ & NS & $0.85^{* * *}$ & $0.22^{\mathrm{NS}}$ \\
\hline $\mathrm{RE}_{\mathrm{T}} \times 100$ & $0.16( \pm 0.01)$ & $0.13( \pm 0.01)$ & $*$ & $0.67 * *$ & $0.43^{\mathrm{NS}}$ \\
\hline REP & $699.07( \pm 1.37)$ & $694.55( \pm 1.59)$ & NS & $0.14^{\mathrm{NS}}$ & $0.32^{\mathrm{NS}}$ \\
\hline RGI & $1.26( \pm 0.02)$ & $1.06( \pm 0.01)$ & $* * *$ & $0.14^{\mathrm{NS}}$ & $0.95 * * *$ \\
\hline ARI & $3.07( \pm 0.33)$ & $7.56( \pm 0.16)$ & $* * *$ & $0.13^{\mathrm{NS}}$ & $0.97 * * *$ \\
\hline CSI & $0.52( \pm 0.02)$ & $0.58( \pm 0.01)$ & $*$ & $0.48 *$ & $0.52 *$ \\
\hline
\end{tabular}

${ }^{1}$ Percentage of field of view.

${ }^{2} n=4$.

${ }^{* * *} P<0.001 .{ }^{* *} P<0.01 .{ }^{*} P<0.05$. ${ }^{\mathrm{NS}}$ Not significant. 
Table 5. Averaged values $( \pm \mathrm{SE})$ for specific leaf area and pigments measured in E. pilularis plants three weeks after treatment began $(n=25)$.

\begin{tabular}{lll}
\hline & \multicolumn{1}{c}{ Healthy } & \multicolumn{1}{c}{ Stressed } \\
\hline Specific leaf area $\left(\mathrm{cm}^{2} \mathrm{mg}^{-1} \mathrm{DW}\right)$ & $0.26( \pm 0.01)$ & $0.11( \pm 0.00)$ \\
Chlorophyll $\left(\mu \mathrm{g} \mathrm{cm}^{-2} \mathrm{FW}\right)$ & $39.2( \pm 1.6)$ & $5.37( \pm 0.2)$ \\
Anthocyanin $\left(\mu \mathrm{g} \mathrm{cm}^{-2} \mathrm{FW}\right)$ & $13.8( \pm 0.8)$ & $51.6( \pm 1.8)$ \\
\hline
\end{tabular}

responses to cold and nutrient deprivation stress are reasonably generic (Close et al. 2001a, 2001b) and both species favour sub-tropical to tropical climates, it is suspected that the chlorophyll content of E. grandis was not reduced as markedly by the stress treatment as E. pilularis.

The average reflectance spectra for each species and treatment shows differences throughout the visible and NIR range (Figure 3). The E. pilularis plants resulted in high reflectance across the NIR wavelengths for both the healthy and stressed plants compared to E. grandis. In both cases the healthy plants had higher reflectance in this spectral region than the plants subjected to the stress treatment which may be related to changes in specific leaf area (Stone et al. 2005) as well as whole-plant structural changes. The stressed E. pilularis plants had higher reflectance than the healthy plants in the red wavelengths (Figure 3), presumably due to reduced chlorophyll content, as detected in the leaf analysis earlier in the stress period (table 5). As reflectance in the stressed E. grandis spectra was not prominently increased in the chlorophyll well region compared to E. pilularis, this suggests that chlorophyll content was not as reduced by the stress treatment in E. grandis as in E. pilularis.

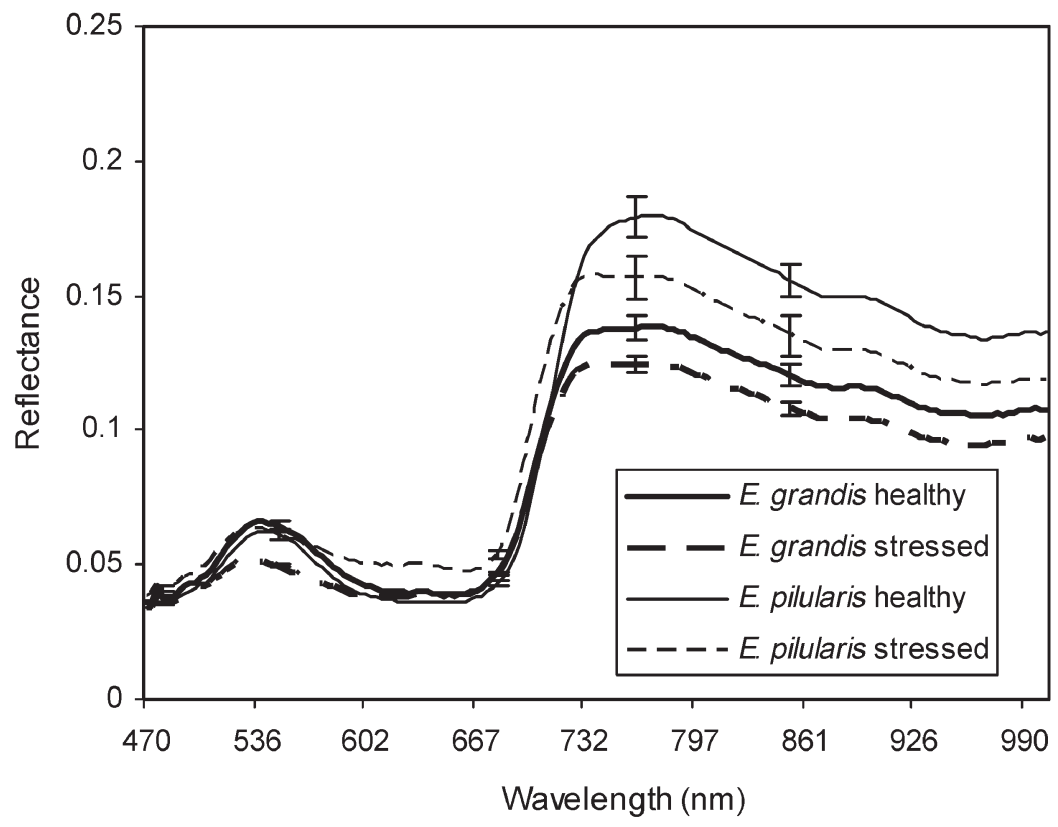

Figure 3. Averaged reflectance spectra $( \pm \mathrm{SE})$ for healthy E. grandis and E. pilularis and "stressed" E. grandis (red discolouration) and E. pilularis (red discoluration and reduced leaf cover) plants. 
Shifts of the red edge slope maxima to lower wavelengths have been well linked to decreased chlorophyll content (Curran 1990, Filella and Peñuelas 1994, Gitelson et al. 1996, Datt 2000). Comparison of red edge position shifts in this data showed that stressed E. pilularis plants had a REP shifted approximately $15 \mathrm{~nm}$ lower from the values of healthy $E$. pilularis (table 3) but this was only approximately $5 \mathrm{~nm}$ (table 4) for E. grandis. While the absolute difference in the shift was greater for $E$. pilularis, the position of the red edge maxima was essentially identical $(695 \mathrm{~nm})$ for the stressed plants of both species (tables 3 and 4).

Calculation of a range of spectral indices using the E. pilularis data revealed that all except the $\mathrm{RE}_{\mathrm{ls}}$ could be used to detect significant differences above the $10 \%$ level between the crown scenes of the healthy and stressed plants, based on the one-way ANOVA (table 3). Regression between the results for each spectral index and the percentage total leaf cover showed that a number of indices had strong and highly significant correlations, with $\mathrm{NDVI}_{\text {narrow, }} \mathrm{RE}_{\mathrm{T}}$ and MCARI2 (or MTVI2) all explaining $>90 \%$ of the variance in cover. These indices have been well correlated with leaf area index in other studies (Carlson and Ripley 1997, Coops et al. 2004, Haboudane et al. 2004). The REP, CSI, DMI and FFRI also had strong and significant relationship with leaf cover (table 3 ). As the latter two indices were designed specifically for chlorophyll content estimation, the data here supports their value in studies of vegetation stress. Regression of indices against the percentage of red leaves visible in the crown scene revealed that while most of those indices which performed best for estimation of leaf cover NDVI $_{\text {narrow }}, \mathrm{RE}_{\mathrm{T}}$ and MCARI2 or MTVI2) were not significantly correlated with percentage red leaves for E. pilularis (table 3) the REP, DMI and CSI were reasonably well correlated. The RGI had the strongest and most significant relationship with percentage of red leaves, followed by the ARI (table 3 ) which supports their intended purpose.

Analysis of the E. grandis spectral data revealed different results, in that only three indices detected significant differences above the $10 \%$ level between the healthy and stressed plants with the one-way ANOVA (table 4). Those indices which produced most significant results were the RGI and ARI, again, as expected. This highlights that the main difference between the healthy and stressed E. grandis plants was the proportion of red leaves, not a change in leaf cover (table 4) as opposed to E. pilularis. This is also highlighted by the fact that the ARI and RGI gave highly significant and very strong correlations with the percentage of red leaves for E. grandis (table 4).

One index that has provided contradictory results for both species is the $\mathrm{RE}_{\mathrm{ls}}$. This was not associated with a significant difference between the healthy and stress treatments for either species. It had a significant and strong relationship with percentage total leaf cover for E. grandis (table 4) but not for E. pilularis (table 3). Coops et al. (2004) found that the slope of the total red edge was more strongly correlated to crown density than the lower red edge slope for some native eucalypt species, to a degree which is similar to results found here with E. grandis for correlation with total leaf cover (table 4). In our study of E. pilularis the lower red edge slope was not significantly different for stressed and healthy plants nor was it correlated to the percentage leaf cover data (table 3 ). The presence of anthocyanins may weaken the relationship between the red edge indices and chlorophyll content (Curran et al. 1991) in the stressed plants and contribute to contradictory results for the $\mathrm{RE}_{1 \mathrm{~s}}$. 
In general, this study highlights the way in which different eucalypt species respond to the same stress and how that influences spectral behaviour. That is, exposure to cold and nutrient deprivation in E. pilularis led to marked changes in leaf cover but not in $E$. grandis, and a much more reduced level of chlorophyll in $E$. pilularis than is suspected in E. grandis. Species differences were also examined in native eucalypt-dominated forests which were in poor or good health (Coops et al. 2004). While all four indices $\left(\mathrm{RE}_{\mathrm{ls}}, \mathrm{RE}_{\mathrm{T}}\right.$, CSI and $\left.\mathrm{RGI}\right)$ tested in that study produced strong and significant correlations with red leaves in E. paniculata, the correlations of all indices were poor for E. saligna and only the RGI was significant across all species tested. In addition to considerations of different responses to stress, phenological differences are also likely to contribute to variation within and between crowns (Stone et al. 2005).

\subsection{Use of different backgrounds for E. globulus}

Although the plants were moved slightly while the background surface was changed, analysis of the photographs showed there was no significant difference in the amount of leaf material in the spectroradiometer field of view between the treatments for this study (table 6). Averaged reflectance data reveal that across the whole spectrum, there were distinct and consistent differences between spectra of the same plants when background type changed (figure 4). The yellow mudstone soil ("bright") had highest reflectance throughout the spectrum, followed by brown sandy soil ("dull") and the black canvas. Comparison between the dull and bright soil in this study is similar in pattern to simulated data for canopy reflectance of grapevines with either bright or dark soil (Zarco-Tejada et al. 2005).

Calculation of the NDVI spectral indices and those designed to improve upon it (SAVI, OSAVI, TCARI/OSAVI, MCARI2 and MTVI2) showed that significant

Table 6. Leaf cover percentage and averaged values $( \pm$ SE) of spectral indices $(n=6)$ for healthy E. globulus with differing background surfaces ("bright"=yellow mudstone soil, "dull"= brown sandy soil) with $P$ values from a one-way ANOVA.

\begin{tabular}{lcccc}
\hline & Bright soil & Dull soil & Black canvas & $P$ (ANOVA) \\
\hline $\begin{array}{l}\text { Image analysis } \\
\text { Leaf cover }\end{array}$ & $60.9 \pm 2.7$ & $61.8 \pm 3.3$ & $62.0 \pm 2.5$ & NS \\
Reflectance indices & & & & \\
NDVI $_{\text {LANDSAT }}$ & $0.68( \pm 0.01)$ & $0.73( \pm 0.01)$ & $0.78( \pm 0.01)$ & $* * *$ \\
NDVI & $0.43( \pm 0.01)$ & $0.49( \pm 0.01)$ & $0.59( \pm 0.01)$ & $* * *$ \\
SAVI & $0.99( \pm 0.01)$ & $1.06( \pm 0.01)$ & $1.13( \pm 0.01)$ & $* * *$ \\
OSAVI & $0.38( \pm 0.01)$ & $0.42( \pm 0.01)$ & $0.48( \pm 0.01)$ & $* * *$ \\
TCARI/OSAVI & $0.47( \pm 0.02)$ & $0.39( \pm 0.01)$ & $0.33( \pm 0.02)$ & $* * *$ \\
MCARI2 & $0.29( \pm 0.02)$ & $0.29( \pm 0.01)$ & $0.30( \pm 0.01)$ & NS \\
MTVI2 & $0.29( \pm 0.02)$ & $0.29( \pm 0.01)$ & $0.30( \pm 0.01)$ & NS \\
DMI & $0.48( \pm 0.02)$ & $0.50( \pm 0.01)$ & $0.48( \pm 0.02)$ & NS \\
FRRI & $1.68( \pm 0.04)$ & $1.84( \pm 0.04)$ & $2.15( \pm 0.06)$ & $*$ \\
RE 1 ls $\times 100$ & $0.53( \pm 0.02)$ & $0.49( \pm 0.02)$ & $0.47( \pm 0.02)$ & NS \\
RE & $0.43( \pm 0.02)$ & $0.40( \pm 0.02)$ & $0.38( \pm 0.02)$ & NS \\
REP & $704.84( \pm 0.27)$ & $705.52( \pm 0.36)$ & $704.48( \pm 0.21)$ & NS \\
RGI & $1.00( \pm 0.01)$ & $0.94( \pm 0.01)$ & $0.81( \pm 0.01)$ & $* * *$ \\
ARI & $1.29( \pm 0.09)$ & $1.53( \pm 0.10)$ & $1.71( \pm 0.13)$ & NS \\
CSI & $0.55( \pm 0.02)$ & $0.49( \pm 0.01)$ & $0.41( \pm 0.01)$ & $* * *$ \\
\hline
\end{tabular}

${ }^{1}$ Percentage of field of view. 


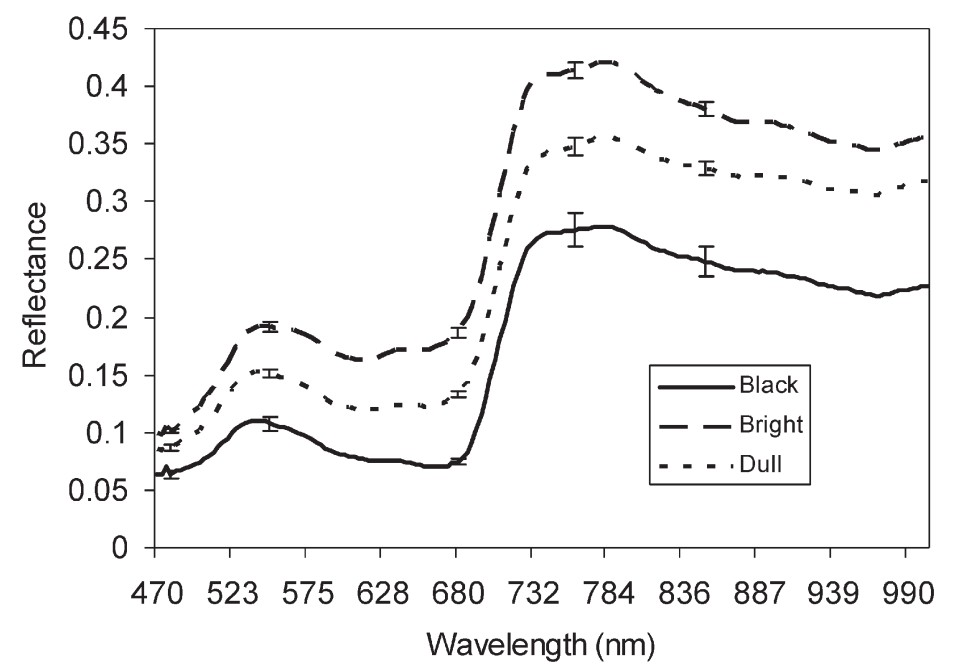

Figure 4. Averaged spectra $( \pm \mathrm{SE})$ of healthy E. globulus $(n=6)$ when different background surfaces were used ("black"=canvas, "bright"=yellow mudstone soil, "dull"=brown sandy soil).

differences between the crown scenes were detected for all but the latter two indices. Whilst SAVI (Huete 1988) and OSAVI (Rondeaux et al. 1996) were developed to minimize the influence of differences in soil background, they did not make any significant improvement from the broad or narrow band NDVI used in this study and nor did the combined index. However, the more recently developed combined indices of MCARI2 and MTVI2 (Haboudane et al. 2004) were not influenced significantly by the changing background surface.

The red edge slope and position indices, the DMI and ARI showed no significant effect of differing background between the crown scenes. In assessments of spectral indices suitable for grapevine condition, the red edge indices provided good correlations with chlorophyll whilst soil type changed, as opposed to NDVI and other traditional indices which were greatly influenced by soil type (Zarco-Tejada et al. 2005). Although absolute reflectance was altered with each background type, the slope of the red edge feature was not altered and therefore indices using the slope of the red edge may have the potential for remote sensing of plantations where soil types change substantially and there is little understorey. Curran (1990) used spectral mixture analysis to demonstrate that if background vegetation had a similar red edge to the canopy, then the overall reflectance would be an average of the two, but if the understorey vegetation was different then the canopy relationship with red edge would be discontinuous. Our vegetation simulation is simplistic, in that it only includes one stratum, the canopy. In a realistic field environment, however, understorey vegetation may impact on the apparent success of this index. The fact that the DMI was unaffected by background in our study but a similar index (i.e. Datt 1999a, 1999b) was poorly correlated with chlorophyll in a study of native eucalypt forest (Coops et al. 2003b) may be cause to question the general applicability of these results.

The CSI and RGI differed significantly between the background types and therefore while they have shown promise to detect leaf cover change and red discolouration respectively, the indices may not be robust for applications where 
background changes in soil occur. The FRRI did not detect a difference between the two soils but the black canvas produced a significantly different result (table 6). While the RGI showed a significant difference between background types, the difference between averages values was actually smaller than for the ARI (the values for which had high standard error and therefore resulted in no significant difference being detected by the ANOVA). Therefore there is some uncertainty as to whether the ARI or RGI would perform better under realistic field conditions.

\section{Conclusion}

A number of conclusions can be drawn from these crown-level studies:

- When defoliation treatments (in E. globulus) or stress (in E. pilularis) resulted in large differences in leaf cover, the red edge indices (REP, $R E_{T}$ and $R_{1 s}$ for E. globulus but only REP and $\mathrm{RE}_{\mathrm{T}}$ in the E. pilularis experiment), two NDVIs and MCARI2 (or MTVI2) were most strongly correlated to leaf cover. The red edge indices and MCARI 2 or MTVI2 were unaffected by the background types used in this study while the NDVIs were affected.

- The percentage of red leaves was most strongly correlated with the ARI and RGI in both E. grandis and E. pilularis. Based on results from the E. globulus background study, the RGI may be more affected by background differences than the ARI, however the performance of these indices needs to be further compared in realistic field environments.

- Defoliation from the upper crown was much easier to detect with spectral data than defoliation from the lower crown, although more leaves were removed from the upper crown treatment.

- To develop robust indices it is important to understand how particular stresses affect plant condition, as it may vary with species. For example, exposure to cold and nutrient deprivation in E. pilularis lead to marked changes in leaf cover but not in E. grandis and a much more reduced level of chlorophyll in E. pilularis than is suspected in E. grandis.

- Performance of indices tested in native eucalypt forests with poor health (Coops et al. 2004) was in reasonable agreement with our results in terms of correlations with red edge indices being strong for leaf cover (cf. crown density) and the RGI being good for redness and damage. Our study suggests there are numerous other indices which may perform as well or better and warrant testing with remotely-sensed data of eucalypt plantations.

- No single VI was robust in all three trials and therefore detection of different symptoms of stress (i.e. defoliation, chlorosis or reddening) requires use of individual indices. These types of damage, as well as understorey, soil and atmospheric effects need to be characterized for specific damaging processes and plant structures in order to select the optimal VI (e.g. Broge and Leblanc 2001).

The value of the experimental system used in this study is that it is easy to manipulate and quantify plant and background factors and therefore assess their contribution to spectral data. However, it remains an artificial system and application of indices will differ to a field situation. The spectroradiometer is suitable for use in the field but would be limited to young plants due to technical difficulties in positioning the probe far enough above the crown. Further studies of 
this nature may be useful as an intermediate between leaf- and canopy-scale research to improve the capability of remote sensing to assess forest health.

Studies such as this will assist in developing the best vegetation indices for detection and/or quantification of a variety of eucalypt plantation crown conditions, at a suitable resolution with sensors currently available in Australia. Some of the most promising indices in this study use narrow wavebands (i.e. RE $\mathrm{T}_{\mathrm{T}}$, MCARI2 or MTVI2 and the ARI) and will require use of hyperspectral instruments or preselection of narrow filtered wavebands for multispectral instruments such as DMSV (Stone et al. 2004). However, the RGI can be used with broad-band multispectral data such as that from QUICKBIRD and IKONOS (Wulder et al. 2006) and may be valuable in some situations.

\section{Acknowledgements}

This research was funded by an Australian Research Council Linkage grant (LP0453591) and Forestry Tasmania, Forests and Industries Council of Tasmania, Forests NSW, Gunns Ltd. and WAPRES. We thank Stephen Ridge for assistance while involved in a Summer Studentship supported by the Tasmanian Institute of Agricultural Research. Mr. Malcolm Hall (CSIRO Forestry) assisted with maintenance of glasshouse material and the stress study. Dr. Neil Sims and Dr. Darius Culvenor (Ensis Remote Sensing Research Group) contributed useful discussion for developing the crown-scale system. Dr. Sims, Dr. Glenn Newnham and Ass. Prof. Mary Martin provided helpful comments which improved earlier versions of this paper.

\section{References}

Arnon, D.I., 1949, Copper enzymes in isolated chloroplasts. Polyphenoloxidases in Beta vulgaris. Plant Physiology, 24, pp. 1-15.

ASNER, G.P., 1998, Biophysical and biochemical sources of variability in canopy reflectance. Remote Sensing of Environment, 64, pp. 234-253.

Broge, N.H. and Leblanc, E., 2001, Comparing prediction power and stability of broadband and hyperspectral vegetation indices for estimation of green leaf area index and canopy chlorophyll density. Remote Sensing of Environment, 76, pp. 156-172.

CARlson, T.N. and Ripley, D.A., 1997, On the relation between NDVI, fractional vegetation cover and leaf area index. Remote Sensing of Environment, 62, pp. 241-252.

CArnegie, A.J. and Ades, P.K., 2003, Mycosphaerella leaf disease reduces growth of plantation-grown Eucalyptus globulus. Australian Forestry, 66, pp. 113-119.

CArter, G.A., 1993, Responses of leaf spectral reflectance to plant stress. American Journal of Botany, 80, pp. 239-243.

CARTER, G.A., 1994, Ratios of leaf reflectance in narrow wavebands as indicators of plant stress. International Journal of Remote Sensing, 15, pp. 697-703.

Choinski JR, J.S., RAlPh, P. and EAmus, D., 2003, Changes in photosynthesis during leaf expansion in Corymbia gummifera. Australian Journal of Botany, 51, pp. 111-118.

Close, D.C., Battaglia, M., Davidson, N.J. and Beadle, C.L., 2004, Within-canopy gradients of nitrogen and photosynthetic activity of Eucalyptus nitens and Eucalyptus globulus in response to nitrogen nutrition. Australian Journal of Botany, 52, pp. 133-140.

Close, D.C. and Beadle, C.L., 2003, The ecophysiology of foliar anthocyanin. The Botanical Review, 69, pp. 149-161.

Close, D.C., Beadle, C.L. and Hovenden, M.J., 2001a, Cold-induced photoinhibition and foliar pigment dynamics of Eucalyptus nitens seedlings during establishment. Australian Journal of Plant Physiology, 28, pp. 1133-1141. 
Close, D.C., Davies, N.W. and Beadle, C.L., 2001b, Temporal variation of tannins (galloylglucoses), flavonols and anthocyanins in leaves of Eucalyptus nitens seedlings: implications for light attenuation and antioxidant activities. Australian Journal of Plant Physiology, 28, pp. 269-278.

Close, D.C., McArthur, C., Hagerman, A.E. and Fitzgerald, H., 2005, Differential variation of leaf chemistry in eucalypt seedlings due to variation in whole-plant nutrient availability. Phytochemistry, 66, pp. 215-221.

Coops, N.C., Delahaye, A. and Pook, E., 1997, Estimation of eucalypt forest leaf area index on the south coast of New South Wales using Landsat MSS data. Australian Journal of Botany, 45, pp. 757-769.

Coops, N.C., Stanford, M., Old, K., Dudzinski, M., Culvenor, D. and Stone, C., 2003a, Assessment of Dothistroma needle blight of Pinus radiata using airborne hyperspectral imagery. Phytopathology, 93, pp. 1524-1532.

Coops, N.C. and STONE, C., 2005, A comparison of field-based and modelled reflectance spectra from damaged Pinus radiata foliage. Australian Journal of Botany, 53, pp. 417-429.

Coops, N.C., Stone, C., Culvenor, D.S. and Chisholm, L., 2004, Assessment of crown condition in eucalypt vegetation by remotely sensed optical indices. Journal of Environmental Quality, 33, pp. 956-964.

Coops, N.C., Stone, C., Culvenor, D.S., Chisholm, L. and Merton, R., 2003b, Chlorophyll content in eucalypt vegetation at the leaf and canopy scales as derived from high resolution spectral data. Tree Physiology, 23, pp. 23-31.

CurRan, P.J., 1990, Exploring the relationship between reflectance red-edge and chlorophyll content in slash pine. Tree Physiology, 7, pp. 33-48.

Curran, P.J., Dungan, J.L., Macler, B.A. and Plummer, S.E., 1991, The effect of a red leaf pigment on the relationship between red edge and chlorophyll concentration. Remote Sensing of Environment, 35, pp. 69-76.

DATT, B., 1998, Remote sensing of chlorophyll $a$, chlorophyll $b$, chlorophyll $a+b$ and total carotenoid content in eucalyptus leaves. Remote Sensing of Environment, 66, pp. 111-121.

DATT, B., 1999a, A new reflectance index for remote sensing of chlorophyll content in higher plants: tests using Eucalyptus leaves. J. Plant Physiol., 154, pp. 30-36.

DAtT, B., 1999b, Visible/near infrared reflectance and chlorophyll content in Eucalyptus leaves. International Journal of Remote Sensing, 20, pp. 2741-2759.

DAtT, B., 2000, Red edge shifts for detecting phenologic change and stress symptoms in evergreen eucalyptus forests. In 10th Australasian Remote Sensing and Photogrammetry Conference, Adelaide, Australia (Adelaide, Australia: Casual Productions), pp. 863-874.

DAwson, T.P. and CURRAN, P.J., 1998, A new technique for interpolating the reflectance red edge position. International Journal of Remote Sensing, 19, pp. 2133-2139.

Demetriades-Shah, T.H., Steven, M.D. and Clark, J.A., 1990, High resolution derivative spectra in remote sensing. Remote Sensing of Environment, 33, pp. 55-64.

Fassnacht, K.S., Gower, S.T., MacKenzie, M.D., Nordheim, E.V. and Lillesand, T.M., 1997, Estimating the leaf area index of north central Wisconsin forests using the Landsat Thematic Mapper. Remote Sensing of Environment, 61, pp. 229-245.

Filella, I. and PeÑuelas, J., 1994, The red edge position and shape as indicators of plant chlorophyll content, biomass and hydric status. International Journal of Remote Sensing, 15, pp. 1459-1470.

GAMON, J.A. and Surfus, J.S., 1999, Assessing leaf pigment content and activity with a reflectometer. New Phytologist, 143, pp. 105-117.

Genstat, 2003, In Genstat 7, L.A. Trust (Ed.) (Rothamsted: Rothamsted Experimental Station).

Gitelson, A.A., Gritz, Y. and Merzlyak, M.N., 2003, Relationships between leaf chlorophyll content and spectral reflectance and algorithms for non-destructive 
chlorophyll assessment in higher plant leaves. Journal of Plant Physiology, 160, pp. 271-282.

Gitelson, A.A., Kaufman, Y.J., Stark, R. and Rundquist, D., 2002, Novel algorithms for remote estimation of vegetation fraction. Remote Sensing of Environment, 80, pp. 76-87.

Gitelson, A.A., Merzlyak, M.N. and Chivkunova, O.B., 2001, Optical properties and nondestructive estimation of anthocyanin content in plant leaves. Photochemistry and Photobiology, 74, pp. 38-45.

Gitelson, A.A., Merzlyak, M.N. and Lichtenthaler, H.K., 1996, Detection of red edge position and chlorophyll content by reflectance measurements near $700 \mathrm{~nm}$. Journal of Plant Physiology, 148, pp. 501-508.

Haboudane, D., Miller, J.R., Pattey, E., Zarco-Tejada, P.J. and Strachan, I.B., 2004, Hyperspectral vegetation indices and novel algorithms for predicting green LAI of crop canopies: Modeling and validation in the context of precision agriculture. Remote Sensing of Environment, 90, pp. 337-352.

Haboudane, D., Miller, J.R., Tremblay, N., Zarco-Tejada, P.J. and Dextraze, L., 2002, Integrated narrow-band vegetation indices for prediction of crop chlorophyll content for application to precision agriculture. Remote Sensing of Environment, 81, pp. 416-426.

Huete, A.R., 1988, A soil-adjusted vegetation index. Remote Sensing of Environment, 25, pp. 295-309.

Jacquemond, S., Ustin, S.L., Verdebout, J., Schmuck, G., Andreoli, G. and HosGOoD, B., 1996, Estimating leaf biochemistry using the PROSPECT leaf optical properties model. Remote Sensing of Environment, 56, pp. 194-202.

JACQUemoud, S. and BARET, F., 1990, PROSPECT: a model of leaf optical properties spectra. Remote Sensing of Environment, 34, pp. 75-91.

Jordan, G.J., Potts, B.M. and Clarke, A.R., 2002, Susceptibility of Eucalyptus globulus spp. globulus to sawfly (Perga affinis ssp. insularis) attack and its potential impact on plantation productivity. Forest Ecology and Management, 160, pp. 189-199.

Karageorgou, P. and Manetas, Y., 2006, The importance of being red when young: anthocyanins and the protection of young leaves of Quercus coccifera from insect herbivory and excess light. Tree Physiology, 26, pp. 613-621.

KAufman, Y.J. and TANRE, D., 1992, Atmospherically resistant vegetation index (ARVI) for EOS-MODIs. IEEE Transactions on Geoscience and Remote Sensing, 30, pp. 261-270.

le Maire G., François, C. and Dufrêne, E., 2004, Towards universal broad leaf chlorophyll indices using PROSPECT simulated database and hyperspectral reflectance measurements. Remote Sensing of Environment, 89, pp. 1-28.

Leckie, D.G., Teillet, P.M., Fedosejevs, G. and Ostaff, D.P., 1988, Reflectance characteristics of cumulative defoliation of balsam fir. Canadian Journal of Forest Research, 18, pp. 1008-1016.

LiCHTENTHALER, H.K., 1996, Vegetation stress: an introduction to the stress concept in plants. Journal of Plant Physiology, 148, pp. 4-14.

LOCH, A.D. and FlOYD, R.B., 2001, Insect pests of Tasmanian blue gum, Eucalyptus globulus globulus, in south-western Australia: History, current perspectives and future prospects. Austral Ecology, 26, pp. 458-466.

MacCioni A., Agati, G. and Mazzinghi, P., 2001, New vegetation indices for remote sensing of chlorophylls based on leaf directional reflectance spectra. Journal of Photochemistry and Photobiology B: Biology, 61, pp. 52-61.

Mancineldi, A.L., HuAng Yang, C., Lindquist, P., Anderson, O.R. and Rabino, I., 1975, Photocontrol of anthocyanin synthesis III. The action of streptomycin on the synthesis of chlorophyll and anthocyanin. Plant Physiology, 55, pp. 251-257.

Mohammed, G.H., Noland, T.L., Irving, D., SAmpson, P.H., Zarco-Tejada, P.J. and Miller, J.R., 2000, Natural and stress-induced effects on leaf spectral reflectance in Ontario species, 156, Ontario Forest Research Institute, Sault Ste. Marie. 
Montandon, L.M. and Small, E.E., 2005, The impact of soil reflectance on the quantification of the green vegetation fraction from NDVI. In American Geophysical Union, Fall Meeting, San Francisco, CA, USA (San Francisco, CA, USA: American Geophysical Union).

Pietrzykowski, E., Stone, C., Pinkard, E. and Mohammed, C., 2006, Spectral characterisation of Eucalyptus globulus foliage infected with Mycosphaerella spp. leaf blight. Forest Pathology, 36, pp. 334-348.

Pinkard, E.A., Baillie, C.C., Patel, V., Paterson, S., Battaglia, M., Smethurst, P.J., Mohammed, C., Wardlaw, T. and Stone, C., 2006, Growth responses of Eucalyptus globulus Labill. to nitrogen application and severity, pattern and frequency of artificial defoliation. Forest Ecology and Management, 229, pp. 378-387.

Pinkard, E.A., Battaglia, M. and Mohammed, C.L., 2007, Defoliation and nitrogen effects on photosynthesis and growth of Eucalyptus globulus. Tree Physiology, 27, pp. $1053-1063$.

Pontius, J., Hallett, R.A. and Martin, M.E., 2005, Assessing hemlock decline using visible and near-infrared spectroscopy: indices comparison and algorithm development. Applied Spectroscopy, 59, pp. 836-843.

Pook, E.W., 1985, Canopy dynamics of Eucalyptus maculata Hook. 3. Effects of drought. Australian Journal of Botany, 33, pp. 65-79.

Rolando, C.A. and LitTle, K.M., 2003, Using chlorophyll fluorescence to determine stress in Eucalyptus grandis seedlings. South African Forestry Journal, 197, pp. 5-12.

Rondeaux, G., Steven, M.D. and Baret, F., 1996, Optimization of soil-adjusted vegetation indices. Remote Sensing of Environment, 55, pp. 95-107.

Rouse, J.W., 1974, Monitoring the vernal advancement and retrogradation of natural vegetation (Greenbelt, MD).

Sampson, P.H., Zarco-Tejada, P.J., Mohammed, G.H., Miller, J.R. and Noland, T.L., 2003, Hyperspectral remote sensing of forest condition: estimating chlorophyll content in tolerant hardwoods. Forest Science, 49, pp. 381-391.

SheArer, B.L. and Smith, I.W., 2000, Diseases of eucalypts caused by soilborne species of Phytophthora and Pythium. In Diseases pathogens of eucalypts, P.J. Keane, G.A. Kile, F.D. Podger and B.N. Brown (Eds) (Collingwood, Victoria: CSIRO Publishing).

Sims, D.A. and GAMON, J.A., 2002, Relationships between leaf pigment content and spectral reflectance across a wide range of species, leaf structures and developmental stages. Remote Sensing of Environment, 81, pp. 337-354.

Smith, A.H., Gill, W.M., Pinkard, E.A. and Mohammed, C.L., in press, Changes in anatomy and histochemistry of Eucalyptus globulus and E. nitens leaves with infection by Mycosphaerella species. Forest Pathology.

Snowdon, P., 2000, Nutritional disorders and other abiotic stresses of eucalypts. In Diseases Pathogens of Eucalypts, P.J. Keane, G.A. Kile, F.D. Podger and B.N. Brown (Eds), pp. 385-410 (Collingwood, Victoria: CSIRO Publishing).

StONE, C. and BACON, P.E., 1994, Relationships among moisture stress, insect herbivory, foliar cineole content and the growth or river red gum Eucalyptus camaldulensis. Journal of Applied Ecology, 31, pp. 604-612.

Stone, C., Chisholm, L. and Coops, N., 2001, Spectral reflectance characteristics of eucalypt foliage damaged by insects. Australian Journal of Botany, 49, pp. 687-698.

Stone, C., Chisholm, L. and McDonald, S., 2005, Effects of leaf age and psyllid damage on the spectral reflectance properties of Eucalyptus saligna foliage. Australian Journal of Botany, 53, pp. 45-54.

Stone, C. and Coops, N.C., 2004, Assessment and monitoring of damage from insects in Australian eucalypt forests and commercial plantations. Australian Journal of Entomology, 43, pp. 283-292.

Stone, C., Coops, N.C. and Culvenor, D., 2000, Conceptual development of a eucalypt canopy condition index using high resolution spatial and spectral remote sensing imagery. Journal of Sustainable Forestry, 11, pp. 23-45. 
Stone, C., Coops, N.C., Sims, N.C., Ryan, P.J., Stanford, M. and Goodwin, N., 2004, Remote assessment of pine plantation condition: A handbook describing the use of multi-spectral imagery to measure impacts from three damaging agents of Pinus radiata, 1480 (New South Wales, Australia: CSIRO and State Forests New South Wales).

Thomson, V.P., Nicotra, A.B. and Steinbauer, M.J., 2001, Influence of previous frost damage on tree growth and insect herbivory of Eucalyptus globulus globulus. Austral Ecology, 26, pp. 489-499.

Tomé, M. and Pereira, J.S., 1991, Growth and management of eucalypt plantations in Portugal. In Third Australian Forest Soils and Nutrition Conference on Productivity in Perspective, Sydney, pp. 147-157 (Sydney: Forestry Commission NSW).

Verhoef, W., 1984, Light scattering by leaf layers with application to canopy reflectance modeling: the SAIL model. Remote Sensing of Environment, 16, pp. 125-141.

Wulder, M.A., Dymond, C.C., White, J.C., Leckie, D.G. and Carroll, A.L., 2006, Surveying mountain pine beetle damage of forests: a review of remote sensing opportunities. Forest Ecology and Management, 221, pp. 27-41.

Yoder, B.J. and Pettigrew-Crosby, R.E., 1995, Predicting nitrogen and chlorophyll content and concentrations from reflectance spectra $(400-2500 \mathrm{~nm})$ at leaf and canopy scales. Remote Sensing and Environment, 53, pp. 199-211.

Zarco-Tejada, P.J., Berjón, A., López, -.L., R., Miller, J.R., Martin, P., Cachorro, V., GonzÁlez, M.R. and de Frutos, A., 2005, Assessing vineyard condition with hyperspectral indices: leaf and canopy reflectance simulation in a row-structured discontinuous canopy. Remote Sensing of Environment, 99, pp. 271-287.

Zarco-Tejada, P.J., Miller, J.R., Mohammed, G.H., Noland, T.L. and Sampson, P.H., 2002, Vegetation stress detection through chlorophyll $\mathrm{a}+\mathrm{b}$ estimation and fluorescence effects on hyperspectral imagery. Journal of Environmental Quality, 31, pp. 1433-1441.

Zarco-Tejada, P.J., Miller, J.R., Morales, A., Berjón, A. and Agüera, J., 2004, Hyperspectral indices and model simulation for chlorophyll estimation in opencanopy tree crops. Remote Sensing of Environment, 90, pp. 463-476.

Zarco-Tejada, P.J., Miller, J.R., Noland, T.L., Mohammed, G.H. and Sampson, P.H., 2001, Scaling-up and model inversion methods with narrowband optical indices for chlorophyll content estimation in closed forest canopies with hyperspectral data. IEEE Transactions on Geoscience and Remote Sensing, 39, pp. 1491-1507. 